\title{
Preferential Orientation of Titanium Dioxide Polycrystalline Films Using Atmospheric CVD Technique
}

\author{
Norio TANAKA, Shigeo OHSHIO and Hidetoshi SAITOH \\ Department of Chemistry, Nagaoka University of Technology, 1603-1, Kamitomioka-cho, Nagaoka-shi, Niigata 940-21
}

\author{
常圧 CVD 法による二酸化チタン多結晶膜の優先配向 \\ 田中教雄・大塩茂夫・斎藤秀俊 \\ 長岡技術科学大学化学系, 940-21 新潟県長岡市上富岡町 1603-1
}

\begin{abstract}
Crystalline orientation and growth rate of titanium dioxide polycrystalline films deposited using an airopened chemical vapor deposition apparatus were investigated. The deposition rate of the titanium dioxide films depends on the substrate temperature and the vaporizing temperature of titanium tetra-isopropoxide. $\mathrm{X}$-ray diffraction analysis revealed that the growth orientation of the films was mainly varied with the vaporizing temperature. At relatively low vaporizing temperature, the films were consisted of $\langle 001\rangle$-oriented columnar crystals grown at a minimum deposition rate of $4 \mathrm{~nm} / \mathrm{s}$. In contrast, $\langle 100\rangle$ - and $\langle 211\rangle$-oriented crystallites grew with a maximum deposition rate of $45 \mathrm{~nm} / \mathrm{s}$ at relatively high vaporizing temperature. These results suggest that the concentration of reactant, which is strongly dependent upon the vaporizing temperature, is one of factors which decide the growth rate of each crystal face.
\end{abstract}

[Received November 7, 1996; Accepted April 1, 1997]

Key-words : Atmospheric CVD, Titanium dioxide polycrystalline films, Rapid deposition, Preferential orientation, Columnar crystals, PBC, Growth kinetics, Growth mechanism

\section{Introduction}

There has been considerable interest in rapid film formation techniques of metal oxide in recent years. This interest derives from the outstanding optical and electric properties of these films consisted of randomly oriented nano- or micro-crystallites. At present, we have little understanding of the chemical processes which are involved in and which control metal oxide crystal nucleation and growth in chemical vapor deposition (CVD) processes. This is because there have been few experiments which have simultaneously characterized both the chemical reaction environment and the kinetics of the metal oxide crystalline growth.

According to the model, 1$) \mathrm{Ti}\left(\mathrm{O}-i-\mathrm{C}_{3} \mathrm{H}_{7}\right)_{4}$ which enters a closed reaction chamber is immediately decomposed with heating to form titanium dioxide by the reaction

$$
\begin{aligned}
& \mathrm{Ti}\left(\mathrm{O}-i-\mathrm{C}_{3} \mathrm{H}_{7}\right)_{4} \rightarrow \mathrm{TiO}_{2}+4 \mathrm{CH}_{3}-\mathrm{CH}=\mathrm{CH}_{2} \\
& \quad+2 \mathrm{H}_{2} \mathrm{O}
\end{aligned}
$$

The extremely facile hydrolysis of titanium tetra-alkoxides readily leads to the formation of the hydroxides or hydrated oxides. However, when restricted amounts of water are added, it undergoes partial hydrolysis reactions yielding in some cases products of definite composition as $\mathrm{TiO}_{n}$ $\left.(\mathrm{OR})_{x}{ }^{2}\right)$ This reaction pathway is responsible for change in growth mechanisms of crystalline films, when the reaction proceeds in an air-opened reaction system.

In this experiment, the air-opened reactor operated under an atmospheric pressure ${ }^{3), 4)}$ was designed and used for the rapid deposition of polycrystalline titanium dioxide films. We studied crystalline orientation and the growth rate of the polycrystalline titanium dioxide films synthesized on the glass substrates with various deposition conditions.

\section{Experimental}

Titanium dioxide films were prepared by an atmospheric CVD apparatus with titanium tetra-isopropoxide (Nacalai Tesque) as source complex. Figure 1 shows a schematic diagram of the atmospheric CVD apparatus. The reactant $\mathrm{Ti}\left(\mathrm{O}-i-\mathrm{C}_{3} \mathrm{H}_{7}\right)_{4}$ was loaded in a vaporizer and vaporized in the range from 77 to $130^{\circ} \mathrm{C}$. The reactant vapor was carried by nitrogen gas and sprayed from the nozzle to the substrate. The flow rate of carrier gas was varied in the range from 1.2 to $1.8 \mathrm{dm}^{3} / \mathrm{min}$. The deposition duration was maintained between $30 \mathrm{~s}$ and $540 \mathrm{~s}$ each experiment. The substrate was heated by an electric heater settled behind the substrate. The substrate temperature was varied in the range from 200 to $700^{\circ} \mathrm{C}$. The distance between the nozzle and the substrate was kept constant at $25 \mathrm{~mm}$ through the experiment. A single crystalline wafer of (100) Si and soda lime glass were cut into a size of $15 \times 15 \mathrm{~mm}^{2}$ and used as the substrate materials.

A part of substrate surface was masked from the reactant flow to avoid deposition, so as to make possible the onedimensional step measurement for taking the film thickness by a roughness tester (Surfcom-550 A, Tokyo Seimitsu Co.). The deposition rate was calculated by dividing the film thickness by the deposition duration. X-ray diffractometry (XRD; using RAD No. 2038, Rigaku) was conducted to reveal the crystal structure and the growth orientation. The surface morphology of these films were observed by a scanning electron microscope (SEM; JSM T-300, JEOL) and an atomic force microscope (AFM; SPI-3700, Seiko).

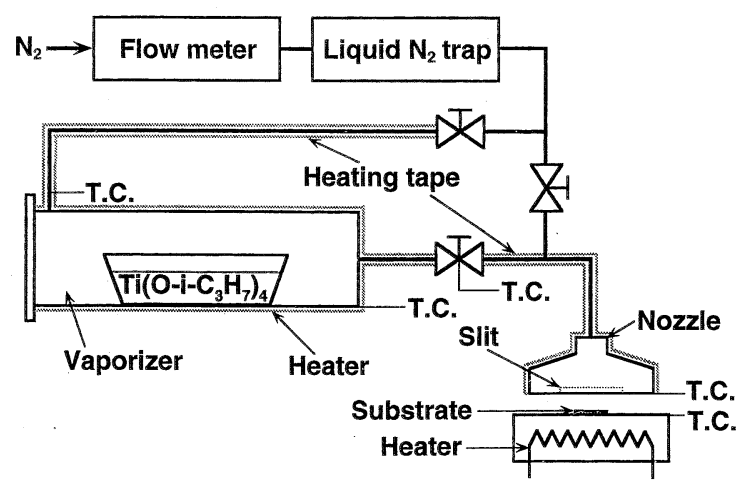

Fig. 1. Schematic diagram of atmospheric CVD apparatus. 
3. Results and discussion

3.1 Preferential orientation of the films

Figure 2 shows the dependencies of deposition rate of the titanium dioxide films on vaporizing and substrate temperatures. The maximum deposition rate increased from 4 to 45 $\mathrm{nm} / \mathrm{s}$ with increasing the vaporizing temperature, reflecting concentration of reactant in a gas phase, from 77 to $130^{\circ} \mathrm{C}$. The dependence of the deposition rate on the substrate temperature indicates that there are the maximum deposition rates at the substrate temperature of approximately $500^{\circ} \mathrm{C}$ for each vaporizing temperatures. This phenomenon is well known as that the reaction mechanism differs under and over temperature in which maximum deposition rate is obtained.5) When the substrate temperature is in the lower region or inhomogeneous gas reaction region, the surface reaction rate is limited by the substrate temperature. In contrast, homogeneous gas phase reaction is dominant in the higher substrate temperature region. This reaction should consume precursors which have important role for the crystal growth, implying the lack of the reactant. Therefore the growth rate suddenly decreases with increasing the substrate temperature. At the homogeneous gas phase reaction region, reactant gas forms nano-crystallites of titanium dioxide which constitutes random oriented polycrystalline titanium dioxide films. Major nano-crystallites are blown off before adsorption on the film surface.

To obtain the oriented growth, the titanium dioxide films were synthesized at the temperature region in which inhomogeneous gas reaction occurs. As the surface reaction was dominant, many polycrystalline films demonstrated oriented growth as shown in Fig. 3. All these samples formed on the soda lime glass substrates had anatase structure having the strongest relative intensity at $2 \theta$ of $25.3^{\circ}$ corresponding to (101) diffraction peak. At the lower vaporizing temperature, for example at $77^{\circ} \mathrm{C}$, the maximum relative intensity appeared as (004) diffraction. This peak intensity suddenly decreased with the increase in the vaporizing temperature. The diffraction pattern of the sample deposited at the vaporizing temperature of $104^{\circ} \mathrm{C}$ became equivalent to the powder pattern. At the higher vaporizing temperature, (200) and (211) peaks became strong. At this condition, the deposition rate was faster than $30 \mathrm{~nm} / \mathrm{s}$.

The degree of orientation estimated by the Lotgering orientation factor $f$ defined as

$$
f=\left(P-P_{0}\right) /\left(1-P_{0}\right)
$$

where $P$ and $P_{0}$ are peak intensity ratio of oriented direction to all directions of oriented sample and of powder of standard specimen, respectively. ${ }^{6)}$ Figure 4 shows relationship between vaporizing temperature and the Lotgering orientation factor for (004) and (200). The value of $f_{(004)}$ was relatively large at lower vaporizing temperature, and decreased with increasing the vaporizing temperature. In contrast, the value of $f_{(200)}$ increased with the temperature, implying that the orientation was changed from $\langle 001\rangle$ to $\langle 100\rangle$. The result also demonstrated a tendency that the degree of the crystal orientation decreased with increasing the substrate temperature. The degree of orientation was also varied by the flow rate of nitrogen gas as shown in Fig. 5, that shows the summarized results of the preferential growth direction.

It is generally known that the degree of preferred orientation is influenced by deposition conditions such as deposi-

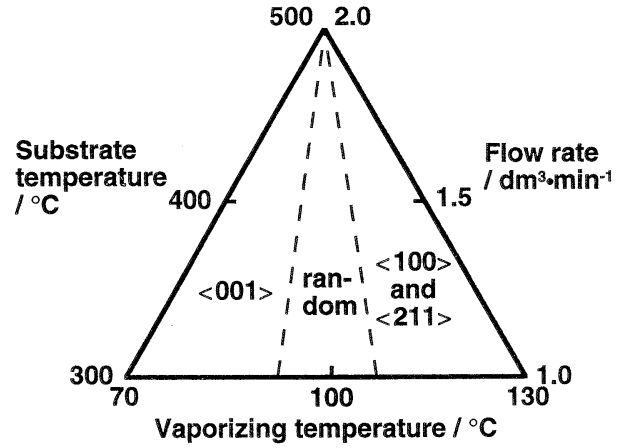

Fig. 5. Favorable growth crientation of titanium dioxide films on glass substrate.

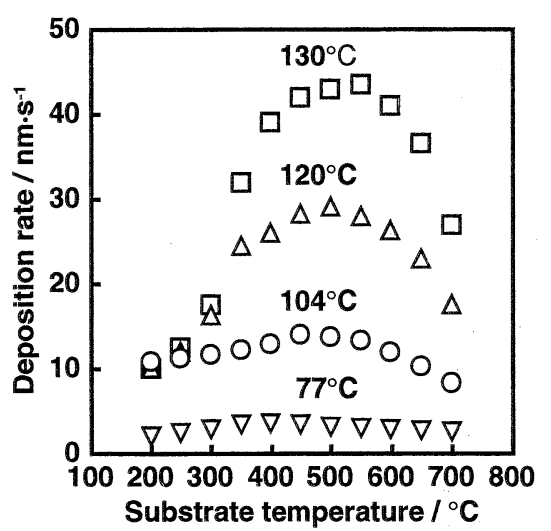

Fig. 2.

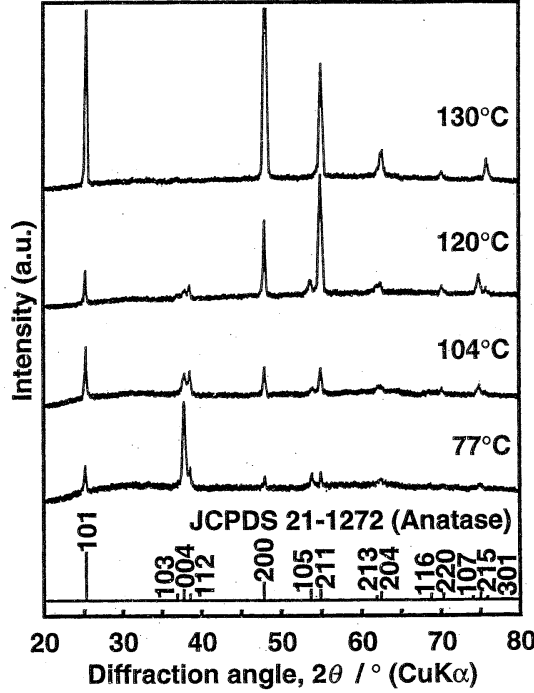

Fig. 3.

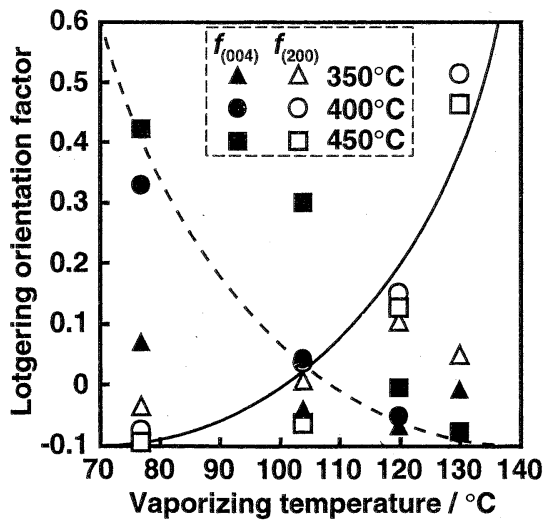

Fig. 4.

Fig. 2. Effects of the substrate temperature and vaporizing temperature on the deposition rate of the films deposited at an $\mathrm{N}_{2}$ flow rate of $1.5 \mathrm{dm}^{3} \cdot \min ^{-1}$.

Fig. 3. X-ray diffraction patterns of titanium dioxide films obtained at various vaporizing temperatures. Deposition conditions kept constant at a substrate temperature of $400^{\circ} \mathrm{C}$ and an $\mathrm{N}_{2}$ flow rate of $1.5 \mathrm{dm}^{3} \cdot \mathrm{min}^{-1}$.

Fig. 4. Effects of the vaporizing temperature and substrate temperature on Lotgering orientation factor of the films deposited at an $\mathrm{N}_{2}$ flow rate of $1.5 \mathrm{dm}^{3} \cdot \mathrm{min}^{-1}$ 
tion rate, substrate temperature, pressure and choice of substrate materials. The mechanism of preferred orientation of CVD films are divided into two classifications, i.e., columnar grain growth with the high growth rate and epitaxial growth. For the former one, Shimogaki and Komiyama ${ }^{7)}$ reported that anatase type titanium dioxide films oriented toward $\langle 110\rangle$ or $\langle 100\rangle$ direction on the glass substrate were obtained by a tubular CVD apparatus at the inner tube temperature above $500^{\circ} \mathrm{C}$ and the relatively high deposition rate of $40 \mathrm{~nm} / \mathrm{s}$. For the latter one, epitaxial anatase films were obtained on (100) surface of the single crystal of (100) $\mathrm{SrTiO}_{3}$ using an ultrahigh vacuum system. ${ }^{1)}$ The orientation of the films is determined by the substrate structure, i.e., the directions of $\langle 001\rangle$ of anatase and $\langle 001\rangle$ of $\mathrm{SrTiO}_{3}$ are the same. Chen et al.1) reported the epitaxial growth of anatase with the relatively slow deposition rate of 0.05 $\mathrm{nm} / \mathrm{s}$.

\subsection{Surface morphology of growth front}

Figure 6 shows SEM micrographs of the surface morphology and the cross-sectional images of the $\langle 001\rangle$ and, $\langle 100\rangle$ and $\langle 211\rangle$-oriented titanium dioxide films. The surface morphology of $\langle 001\rangle$-oriented films indicated lower film density and unclear crystalline facets. On the other hand, $\langle 100\rangle$ and $\langle 211\rangle$-oriented films showed that the crystalline columns having clear facets aggregated densely. The cross-sectional images of both oriented crystallite show typical columnar crystal growth. However, it should be noted that the growth direction was not in agreement with the index of the facet that appears on the top view image. To estimate the facet index of the $\langle 100\rangle$ - and $\langle 211\rangle$-oriented films, AFM observation was carried out as demonstrated in Fig. 7. Typical growth section of the $\langle 100\rangle$ - and $\langle 211\rangle$-oriented crystallite was consisted of three facets. One of them was a relatively flat surface. Other two faces had relatively large steps on the surface and were mutually sloped on either side at the angle of approximately $45^{\circ} \pm 5^{\circ}$ from a horizontal plane. If these stepped faces are indexed as [110] and [110], the line formed by two $\{110\}$ faces is perpendicular to the $\langle 100\rangle$. The angle between this line and the flat surface is in the range between $15^{\circ}$ and $25^{\circ}$, suggesting that the flat sur-
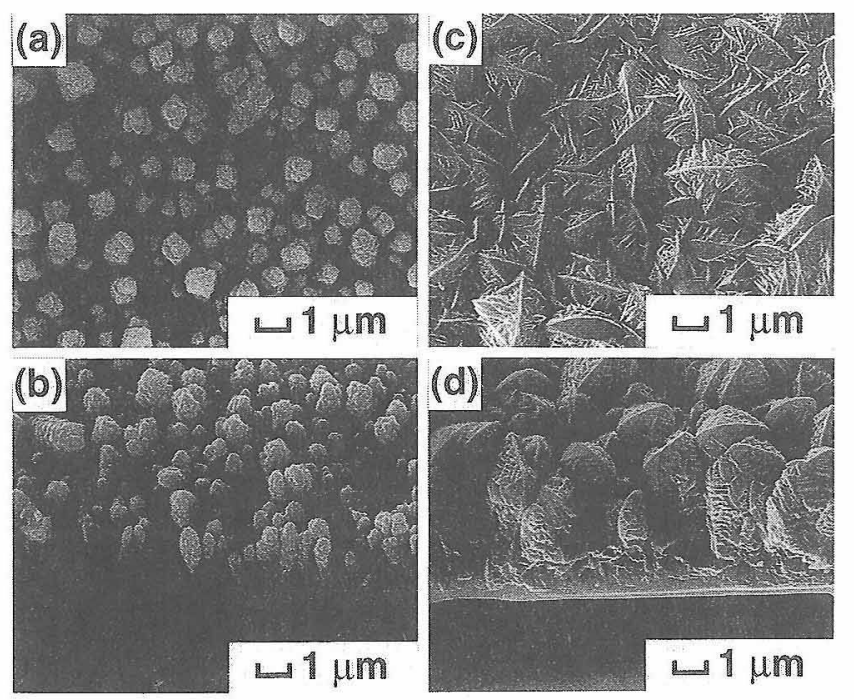

Fig. 6. SEM micrographs of titanium dioxide films on glass substrate. Figures (a) and (b) represent surface and cross sectional images of $\langle 001\rangle$-oriented films deposited at a vaporizing temperature of $77^{\circ} \mathrm{C}$, substrate temperature of $400^{\circ} \mathrm{C}$ and an $\mathrm{N}_{2}$ flow rate of $1.5 \mathrm{dm}^{3} \cdot \mathrm{min}^{-1}$. Figures (c) and (d) indicate surface and cross sectional images of $\langle 100\rangle$ - and $\langle 211\rangle$-oriented films deposited at a vaporizing temperature of $130^{\circ} \mathrm{C}$, substrate temperature of $400^{\circ} \mathrm{C}$ and an $\mathrm{N}_{2}$ flow rate of $1.5 \mathrm{dm}^{3} \cdot \mathrm{min}^{-1}$.

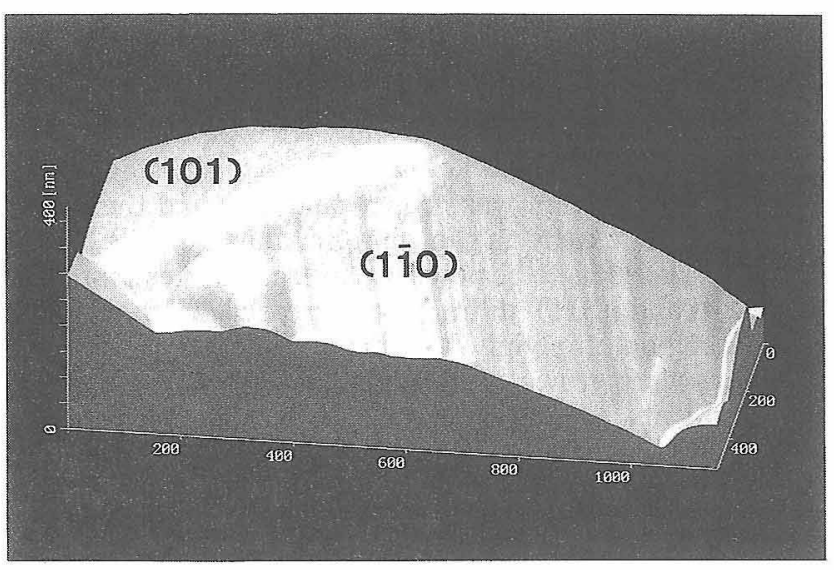

Fig. 7. AFM topographic image of $\langle 100\rangle$ - and $\langle 211\rangle$-oriented titanium dioxide films.

face is (101). According to the SEM micrograph as indicated in Fig. 6, some crystallites indicated line image without flat surface. These crystallites were thought to be $\langle 100\rangle$ oriented. On the other hand, the $\langle 100\rangle$ crystal axis of the crystallites showing flat (101) was tilted at approximately $10^{\circ}-20^{\circ}$ from the growth direction. The growth direction is thought to be $\langle 201\rangle$. Unfortunately, since (201) diffraction of anatase structure is forbidden, relatively strong (211) peak was obtained instead of (201) peak. The X-ray diffraction results well support the interpretation of the AFM results.

In general crystal, there is an uninterrupted chain of strong bonds between the building units. On the projection of the anatase structure along [100], there is a bond chain -Ti-O-Ti-repeated in the slice $d_{011}$. Such a chain is called a Periodic Bond Chain (PBC).8) The PBC should have no dipole moment perpendicular to its direction in order to avoid high surface energies in ionic crystals. Therefore the faces containing two or more PBC's in a layer $d_{\mathrm{hkl}}$ is the most stable faces called $F$ (flat) face. The faces containing no and only one PBC in a layer $d_{\mathrm{hkl}}$ are $K$ (kinked) and $S$ (stepped) faces, respectively. The relationship of the growth rate among these faces is normally given as $R_{\mathrm{F}}<R_{\mathrm{S}}<R_{\mathrm{K}}$. In anatase crystal of titanium dioxide, each titanium atom is surrounded by six oxygen atoms in a distorted octahedron. In the layer $d_{001}$, there are two types of O-Ti-O PBC's which have the electrostatic dipole moment perpendicular to its direction. Since each dipole moment has an opposite polarity, they are canceled. Therefore $\{101\}$ of anatase structure is an $F$ face. By the same reason, $\{001\}$ is also classified to $F$ face. In addition, there is no or one PBC in the layers $d_{220}$ and $d_{200}$, implying $\{110\}$ and $\{100\}$ is $K$ and $S$ faces. Holman and Huege ${ }^{9)}$ have proposed a model that the growth rate is fastest at the tips of the grain which consists polycrystalline films under conditions of mass transport control. In this model a concentration gradient of precursors exists in the gas stream between the tips and grain boundary, suggesting that the tip behave itself like a main adsorption site for arrived precursors. The degree of preferred orientation is dependent upon not only the concentration gradient but also the adsorption coefficient on the crystal face. PBC concept theoretically predict that the adsorption coefficient of precursors is great on $\{100\}$ and $\{110\}$ surface of anatase crystal. The prediction shows good agreement at high growth rate as obtained in our study. A number of crystalline grains possess a high degree of preferred orientation. These growing tips are surround by $F$ face $\{101\}$ and $\{110\}$ faces possessing relatively large steps on their surface. 


\subsection{Possible mechanism of preferential orientation}

For the $\langle 100\rangle$ - and $\langle 211\rangle$-oriented films, the mechanism. of orientation growth was examined by varying the deposition duration. Figures 8 and 9 show XRD pattern and SEM images of titanium dioxide films. At the initial stage of the film growth, the film was grown randomly and the crystal plane was not clearly as shown in SEM image. The diffraction pattern seems to be powder pattern. The peak intensity of (200) and (211) diffraction increased at steady-state growth region, implying that titanium dioxide polycrystalline films were grown along to $\langle 100\rangle$ and $\langle 211\rangle$ directions. The SEM images demonstrated that the crystalline facets became clear with the increase of the deposition duration. The growth mechanism of the $\langle 001\rangle$-oriented crystallites is similar to that of $\langle 100\rangle$ - and $\langle 211\rangle$-oriented films. These results strongly suggest that the growth direction is decided by the growth rate of each crystalline direction, i.e., the growth rate along to the $\langle 100\rangle$ and $\langle 211\rangle$ directions is the fastest in all the growth rates.

In this study, the deposition experiments with the change of $\mathrm{Ti}\left(\mathrm{O}-i-\mathrm{C}_{3} \mathrm{H}_{7}\right)_{4}$ concentration as varying the vaporizing

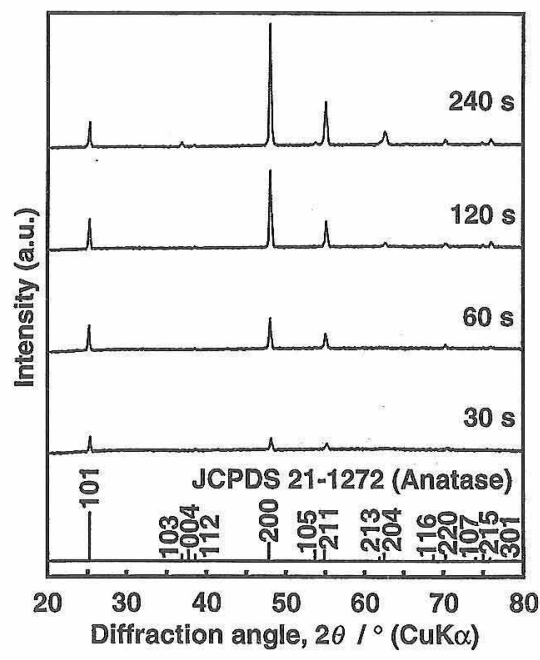

Fig. 8. X-ray diffraction patterns of titanium dioxide films obtained at each deposition duration. Deposition conditions kept constant at a vaporizing temperature of $130^{\circ} \mathrm{C}$, a substrate temperature of $400^{\circ} \mathrm{C}$ and an $\mathrm{N}_{2}$ flow rate of $1.5 \mathrm{dm}^{3} \cdot \mathrm{min}^{-1}$.
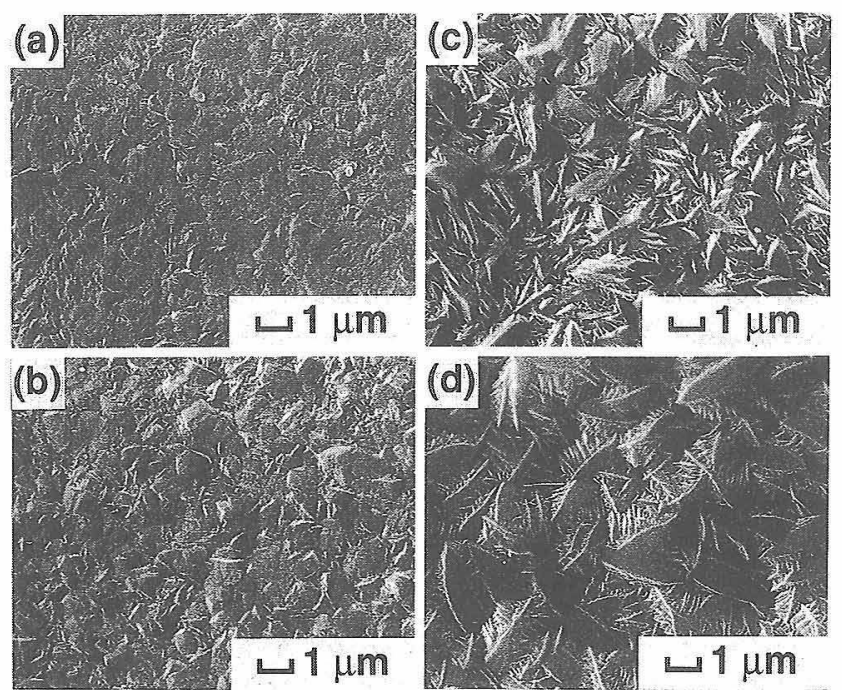

Fig. 9. SEM micrographs of titanium dioxide films obtained at each deposition duration. (a) $30 \mathrm{~s}$, (b) $60 \mathrm{~s}$, (c) $120 \mathrm{~s}$ and (d) $240 \mathrm{~s}$. temperature exhibit that the deposition rate of $\langle 001\rangle$ direction $(R\langle 001\rangle), 4 \mathrm{~nm} / \mathrm{s}$, is slower than that of $\langle 100\rangle$ and $\langle 211\rangle$ directions $\left(R_{\langle 100\rangle,\langle 211\rangle}\right), 40 \mathrm{~nm} / \mathrm{s}$. As following columnar grain growth process, the crystalline direction shows random orientation at the initial nucleation stage with a few exceptions including epitaxial growth. As the time proceeds, the nuclei having the fastest growth direction that is normal to the substrate surface preferentially grow and form the columnar structure over the randomly oriented nucleation layer. This process of selective growth forms columnar structure having a high degree of preferred orientation. Thus relations of growth rate on each direction are described as

\section{$R_{\langle 001\rangle}>R_{\langle 100\rangle}$ and other directions} (lower concentration)

$R_{\langle 100\rangle,} R_{\langle 211\rangle}>R_{\langle 001\rangle}$ and other directions (higher concentration).

The extremely facile hydrolysis of titanium tetraalkoxides readily lead to the formation of the hydroxides or hydrated oxides. However, when restricted amounts of water are added, titanium alkoxides undergo partial hydrolysis reactions yielding in some cases products of definite composition as oxide alkoxides $\mathrm{TiO}_{n}(\mathrm{OR})_{x} \cdot{ }^{2)}$ On increasing the concentration of $\mathrm{Ti}\left(\mathrm{O}-i-\mathrm{C}_{3} \mathrm{H}_{7}\right)_{4}$ during constant water contents, titanium contents of the products decreased. As the surface reaction rate or kinetics is strongly dependent upon the choice of precursors adsorbed on the crystal surface, the concentration of $\mathrm{Ti}\left(\mathrm{O}-i-\mathrm{C}_{3} \mathrm{H}_{7}\right)_{4}$ may be one of the factors which decide the growth rate of each crystal face.

\section{Conclusions}

This investigation revealed the deposition rate and the crystalline orientation of polycrystalline titanium dioxide films deposited by an atmospheric pressure CVD apparatus.

(1) The deposition rate of titanium dioxide films depended on the vaporizing and substrate temperatures. A maximum deposition rate of $45 \mathrm{~nm} / \mathrm{s}$ was obtained at a vaporizing temperature of $130^{\circ} \mathrm{C}$.

(2) The growth orientation varied with deposition conditions. At relatively low vaporizing temperature, the films were consisted of $\langle 001\rangle$ preferentially grown columnar crystals. In contrast, $\langle 100\rangle$ - and $\langle 211\rangle$-oriented crystallites grew at relatively high vaporizing temperature.

(3) Typical growth section of the $\langle 100\rangle$ - and $\langle 211\rangle$ oriented crystallite consisted of relatively flat (101) face and two stepped (110) faces. As the surface of (100) may have great adsorption coefficient for precursor in the gas phase, $\langle 100\rangle$ direction becomes one of the candidates of crystalline growth orientation.

\section{References}

1) S. Chen, M. G. Mason, H. J. Gysling, G. R. Paz-Pujalt, T. N. Blanton, T. Castro, K. M. Chen, C. P. Fictrie, W. L. Gladfelter, A. Fransiosi, P. I. Cohen and J. F. Evans, J. Vac. Sci. Technol., A11, 2419-29 (1993).

2) D. C. Bradley, R. C. Mehrotra and D. P. Gaur, "Metal Alkoxides," Academic Press, London, U. K. (1978).

3) J. Nishino, S. Ohshio and K. Kamata, J. Am. Ceram. Soc., 75, 3469-72 (1992).

4) K. Kamata, J. Nishino, S. Ohshio, K. Maruyama and M. Ohtsuki, J. Am. Ceram. Soc., 77, 505-08 (1994).

5) W. A. Bryant, J. Mater. Sci., 12, 1285-306 (1977).

6) U. Selvaraj, A. V. Prasadarao, S. Komarneni and R. Roy, J. Am. Ceram. Soc., 75, 1167-70 (1992).

7) Y. Shimogaki and H. Komiyama, Yogyo-Kyokai-Shi, 95, 80-85 (1987) (in Japanese).

8) P. Hartman, "Crystal Growth," North-Holland, London, U. K. (1973).

9) W. R. Holman and F. J. Huegel, "CVD I", The Amer. Nuclear Soc., Hinsdale. III, p. 127. 